Im „Journal Club“ werden Originalarbeiten aus der internationalen Fachliteratur referiert und kommentiert.

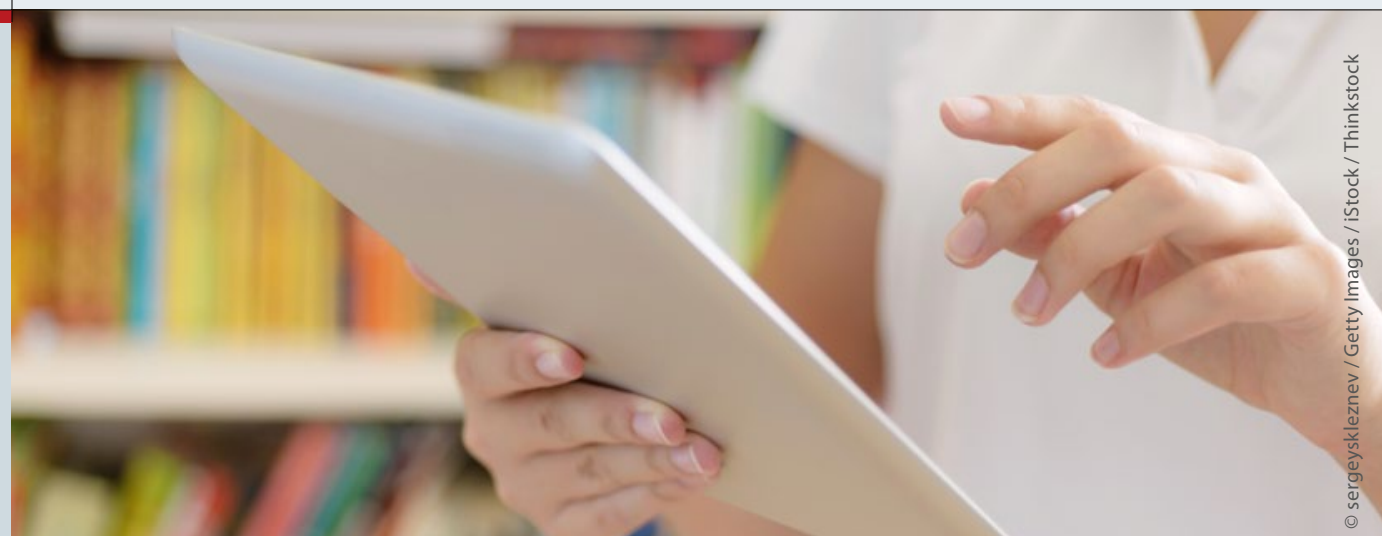

\section{Zu wenig Vitamin D und zu viel Gewicht können Multiple Sklerose bei Kindern auslösen}

\section{Kinder mit einem genetisch bedingten Mangel an Vitamin D und Risikogenen für Übergewicht erkranken gehäuft an MS. Danach könnten wenig Vitamin D und zu viel Gewicht tatsächlich eine MS fördern.}

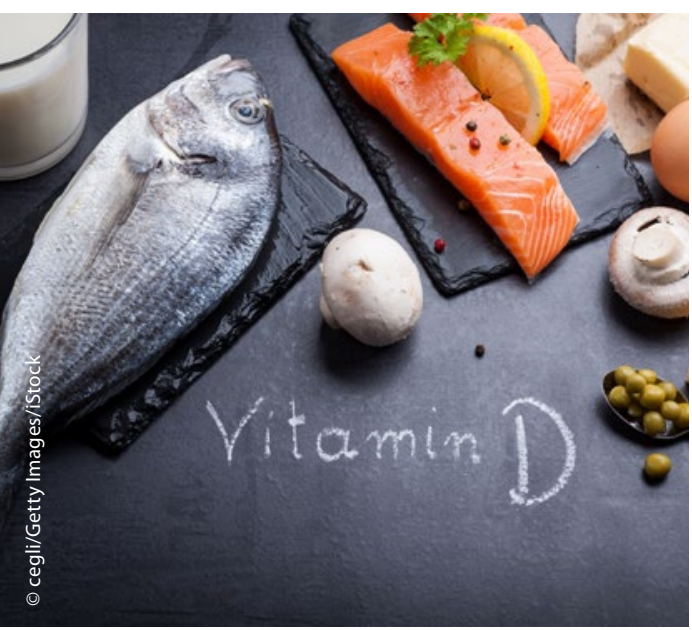

Im Winter ist die Sonnenwirkung für die körpereigene Vitamin D-Produktion zu schwach. Eine Ernährung mit Vitamin Dhaltigen Lebensmitteln ist dann wichtig.

O b und wie stark bestimmte Umweltfaktoren das Risiko für eine Erkrankung beeinflussen, lässt sich nur schwer ermitteln. Epidemiologische Studien liefern lediglich Assoziationen, Interventionsstudien verbieten sich meist oder sind schlicht nicht praktikabel. So weiß man häufig nicht, was Ursache und was Wirkung ist. Zwar ist bekannt, dass wenig Vitamin D mit einem erhöhten MS-Risiko einhergeht, ob Vitamin D aber nur ein Marker für wenig UV-
Licht-Exposition oder einen bestimmten Lebensstil ist oder ob das Vitamin tatsächlich das MS-Risiko beeinflusst, geht aus den meisten Studien nicht hervor. Dazu müsste man gesunde Probanden über Jahre oder gar Jahrzehnte hinweg mit unterschiedlichen Vitamin-D-Dosierungen behandeln.

Solche Experimente gibt es in der Tat, und dazu ist nicht einmal das Einverständnis einer Ethikkommission nötig: Die Natur selbst bringt Menschen mit einer genetischen Ausstattung hervor, die zu unterschiedlich hohen Vitamin-DSpiegeln führt. Ein Team um Dr. Milena Gianfrancesco von der Universität in Berkeley hat daher geschaut, ob sich die entsprechenden Genvarianten auf die MS-Rate bei Kindern auswirken. Sie beschränkten sich auf Minderjährige, weil hier die MS-Risikofaktoren noch weniger erforscht sind als bei Erwachsenen. Zudem schauten sie nach einem Zusammenhang mit dem Gewicht, da dicke Kinder häufiger an MS erkranken als solche mit normalem Gewicht.

\section{Viel Vitamin D, \\ $\mathbf{2 8 \%}$ geringeres MS-Risiko}

Die Wissenschaftler untersuchten Genvarianten mit Einfluss auf den VitaminD-Spiegel sowie auf das Gewicht bei 569 MS-Patienten mit Krankheitsbeginn in der Kindheit sowie rund 16.000 Perso- nen ohne MS. Die Patienten stammten aus diversen MS-Registern der USA und Schweden, die Kontrollen von genomweiten Assoziationsstudien in diesen Ländern. Berücksichtigt wurden die Varianten von drei Genen mit bekanntem Einfluss auf den Vitamin-D-Spiegel sowie knapp 100 Gene mit einer Relevanz für den BMI. Die Forscher schauten also, wie häufig die jeweiligen Varianten bei MS-Kranken und gesunden Kontrollen vorkommen. Daraus erstellten sie einen genetischen Risikoscore.

Für Kinder mit einer Genkombination, die hohe Vitamin-D-Werte begünstigt, berechnete das Team um Gianfrancesco ein 28\% geringeres MS-Risiko. Berücksichtigt wurden dabei neben Alter und Geschlecht auch etwa 100 bekannte MS-Risikogene. Für Genvarianten, die einen hohen BMI fördern, fanden die Wissenschaftler ein um 17\% erhöhtes MS-Risiko.

Sie sehen in diesen Resultaten einen deutlichen Hinweis, wonach sowohl wenig Vitamin D als auch Übergewicht die MS-Gefahr in der Kindheit steigern. Da nicht alle Genvarianten bekannt sind, die Gewicht und Vitamin-D-Spiegel regulieren, könnte der Effekt auch noch größer sein, als er sich aus den Berechnungen der Forscher ergibt. Auf der anderen Seite beweisen die Ergebnisse nicht definitiv, dass Vitamin D und Gewicht das MS-Risiko kausal steuern. Möglicherweise sind auch andere Interaktionen der analysierten Gene die Ursache für ein erhöhtes oder reduziertes MS-Risiko.

(TM)

Gianfrancesco MA et al. Evidence for a causal relationship between low vitamin D, high BMI, and pediatric-onset MS. Neurology 2017, epub March 29, doi: 10.1212/WNL.0000000000003849. 